\title{
Descemet-stripping automated endothelial keratoplasty for vitrectomized cases with traumatic aniridia and aphakic bullous keratopathy
}

This article was published in the following Dove Press journal:

Clinical Ophthalmology

14 September 2012

Number of times this article has been viewed

\author{
Hiroshi Eguchi \\ Tatsuro Miyamoto \\ Fumika Hotta \\ Machiko Tomida \\ Masayuki Inoue \\ Yoshinori Mitamura \\ Department of Ophthalmology, \\ Institute of Health Biosciences, \\ The University of Tokushima \\ Graduate School, Tokushima, Japan
}

Correspondence: Yoshinori Mitamura

Department of Ophthalmology, Institute of Health Biosciences,

The University of Tokushima Graduate School, 3-18-15 Kuramoto, Tokushima 770-8503, Japan

Tel +8I $886337 \mid 63$

Fax $+8|8863| 4848$

Email ymita@clin.med.tokushima-u.ac.jp
Abstract: The surgical indication for Descemet-stripping automated endothelial keratoplasty (DSAEK) is largely limited to phakic or pseudophakic cases of endothelial dysfunction with normal pupils, because the endothelial lenticule is generally attached to the recipient cornea by use of gas tamponade into the anterior chamber. Although it may be desirable for vitrectomized cases with aniridia and aphakic bullous keratopathy without capsule support to undergo DSAEK, one of the major problems is lenticule detachment during surgery or in the postoperative period. To perform DSAEK in such cases, special surgical techniques are needed in order to facilitate adhesion of the lenticule. Herein, we describe a suture technique for attaching the endothelial lenticule in DSAEK for aniridic and aphakic cases that have undergone vitrectomy for traumatic vitreoretinal disease.

Keywords: traumatic aniridia, aphakic bullous keratopathy, Descemet-stripping automated endothelial keratoplasty, vitrectomy

\section{Introduction}

In recent years, Descemet-stripping automated endothelial keratoplasty (DSAEK) for corneal endothelial dysfunction has become popular because of the advantages of less perioperative refractive changes and early visual rehabilitation. ${ }^{1,2}$ In DSAEK, the endothelial lenticule is generally attached to the recipient corneal stroma by gas tamponade into the anterior chamber. Therefore, an aphakic, vitrectomized, and widely iridectomized eye after total lens removal is not considered as a good candidate for DSAEK. In such cases, the endothelial lenticules may fall into the vitreous cavity during surgery or early on the postoperative day. However, it may be desirable for such cases to undergo DSAEK, not only because of the above-described advantages of DSAEK, but also because of the prevention of eyeball collapse during penetrating keratoplasty. To this end, novel techniques that guarantee both a safe manipulation of the lenticule during surgery and postoperative rigid adhesion to the recipient cornea are necessary.

Although previous studies describing suture techniques in DSAEK have been published, ${ }^{3-5}$ these suture techniques were used mainly for inserting or unfolding lenticules without forceps in normal pupils, in which the efficacy of gas tamponade into the anterior chamber is ensured. Price et $\mathrm{al}^{6}$ reported special techniques to prevent the donor tissue from dropping onto the retina in three cases with aniridia and aphakia. The donor tissue was initially inserted only $80 \%$ to $90 \%$ of the way into the eye, leading to one end being held in the incision while a temporarily anchored suture was placed in the peripheral edge of the anterior portion of the donor tissue to secure it to the overlying 
recipient cornea. The fixation suture used to anchor the donor tissue temporarily was then removed.

We have previously performed DSAEK with a suture technique during lenticule insertion using a double-armed 10-0 prolene suture (Pair pak ${ }^{\circledR}$; Alcon Japan, Tokyo, Japan) that was originally designed for intraocular lens ciliary sulcus fixation. ${ }^{7}$ The suture may be used as a lifeline for the lenticule during DSAEK and as a dress-pin for the lenticule after DSAEK in vitrectomized aphakic eyes. Patel et $\mathrm{al}^{8}$ have already reported similar suture techniques in DSAEK for 13 cases with minimal or absent iris-lens diaphragm. Herein, we describe a modified suture technique for the endothelial lenticule in DSAEK for aniridic aphakic cases that have undergone vitrectomy for traumatic vitreoretinal disease.

\section{Surgical technique}

Under general anesthesia, an anterior chamber maintainer was passed through an inferior paracentesis considering a schematic diagram for the use of a 10-0 prolene suture (Figure 1). As reported previously, ${ }^{9}$ the maintainer was connected to a machine for vitrectomy (Millennium ${ }^{\circledR}$; Bausch and Lomb, Rochester, NY) that can supply gas under controlled pressure and that also can supply a balanced saline solution (BSS PLUS ${ }^{\circledR}$; Alcon Japan, Tokyo, Japan) with switchover through a T-shaped stopcock. A conjunctival incision was followed by a scleral tunnel 7 to $8 \mathrm{~mm}$ in width at $2.0 \mathrm{~mm}$ distance from the superior corneal limbus. Descemet's membrane and endothelium were stripped within the planned graft area after a mark with a 7.0-mm diameter trephine was made on the epithelium using crystal violet, while the anterior chamber was filled with air.

The ensuing steps are presented in the supplementary video. After insertion of a handmade glide for the lenticule into the anterior chamber, we prepared the endothelial lenticule on another sterilized table using a microscope. The precut donor cornea was supplied by Sight Life ${ }^{\text {TM }}$ (Seattle, WA) and the endothelial lenticule was cut with a trephine $9.0 \mathrm{~mm}$ in diameter after dissection of the anterior stromal flap. The lenticule was coated with a small amount of viscoelastic device (Viscoat ${ }^{\circledR} 0.5$; Alcon Japan) and was gently folded, with the endothelial side inward, into a "taco" configuration. A curved needle with 10-0 prolene suture was inserted $1.0 \mathrm{~mm}$ length into the edge of the stromal surface of the lenticule at a $1.0-\mathrm{mm}$ distance from both the cut end and diametrical plane. We made markings of these insertion sites on the stroma of the lenticule with crystal violet so that we could pass the needle as accurately as possible through the recipient cornea in a $7.0-\mathrm{mm}$ diameter circle, which was at a $1.0-\mathrm{mm}$ distance from the cut end of the $9.0-\mathrm{mm}$ diameter lenticule. The curved needle was placed into, not passed through, the stroma of the lenticule to prevent the two prolene sutures from tangling (Figure 2).

The lenticule was transferred gently to a surgical field, and folded with the endothelial side inward on a donor insertion spatula (Ousley spatula; Bausch and Lomb). The second straight needle was inserted through the scleral tunnel into the anterior chamber, entering the endothelial side of the recipient superior cornea and exiting the epithelial side at the
A

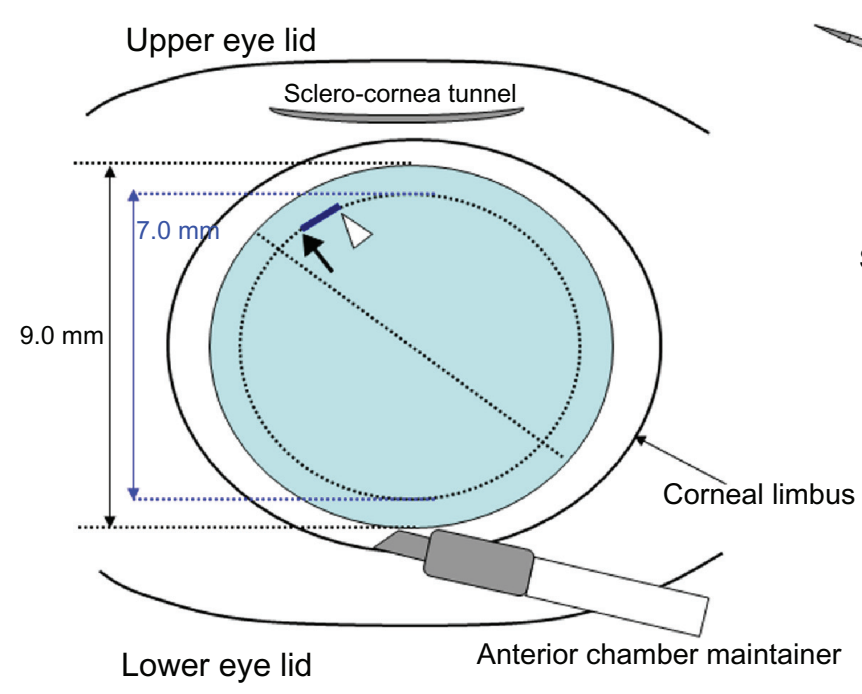

B

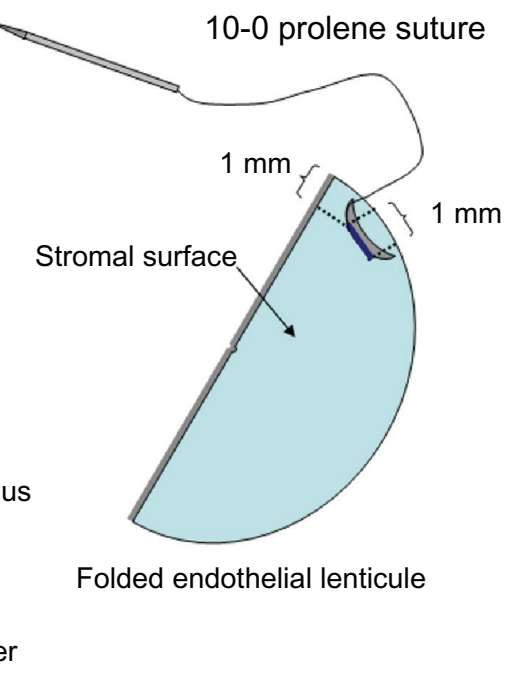

Figure I Schematic diagram for the use of a 10-0 prolene suture in Descemet-stripping automated endothelial keratoplasty. (A) Markings of 7.0 mm in diameter, and points where the needle will be passed. The black arrow and white arrowhead show the points through which the straight needle and curved needle will be passed, respectively. (B) A folded endothelial lenticule and markings through which the curved needle will be passed. 


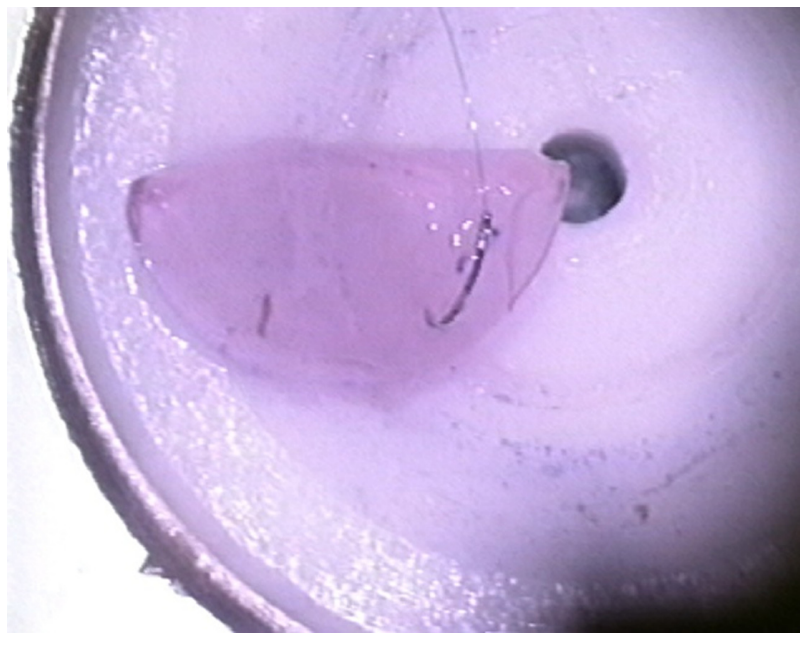

Figure 2 The curved needle is placed into, not passed through, the stroma of the lenticule to prevent the two prolene sutures from tangling.

circle marked by the $7.0-\mathrm{mm}$ diameter trephine (Figure 3 ). After the straight needle had exited, a curved needle stuck in the stromal surface of the lenticule was passed through completely and pulled out at a $1.0-\mathrm{mm}$ distance from the previous insertion site. This needle also entered the endothelial side of the recipient cornea and exited the epithelial side at the point marked by the $7.0-\mathrm{mm}$ diameter trephine and $1.0-\mathrm{mm}$ distance from which the straight needle passed through (Figure 4). The endothelial lenticule was opened and placed on a large amount of viscoelastic at the superior side of a handmade glide endothelial side downward. After temporary suspension of the BSS supply through the anterior maintainer via switchover of the T-shaped stopcock, the endothelial lenticule was inserted into the anterior chamber with one gentle action using an anterior capsule forceps (Ikeda angled

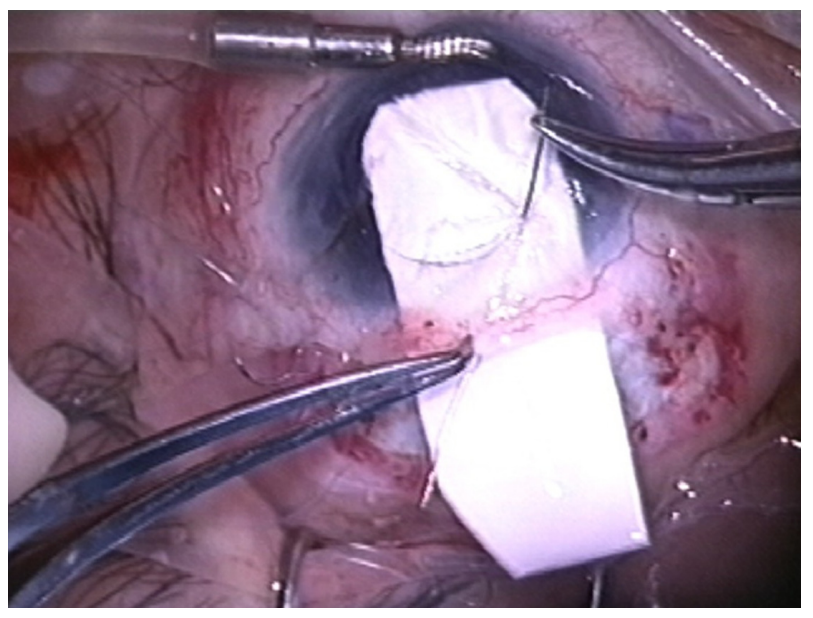

Figure 3 The second straight needle is inserted through the scleral tunnel into the anterior chamber, entering the endothelial side of the recipient superior cornea and exiting the epithelial side at the circle marked by the 7.0-mm diameter trephine.

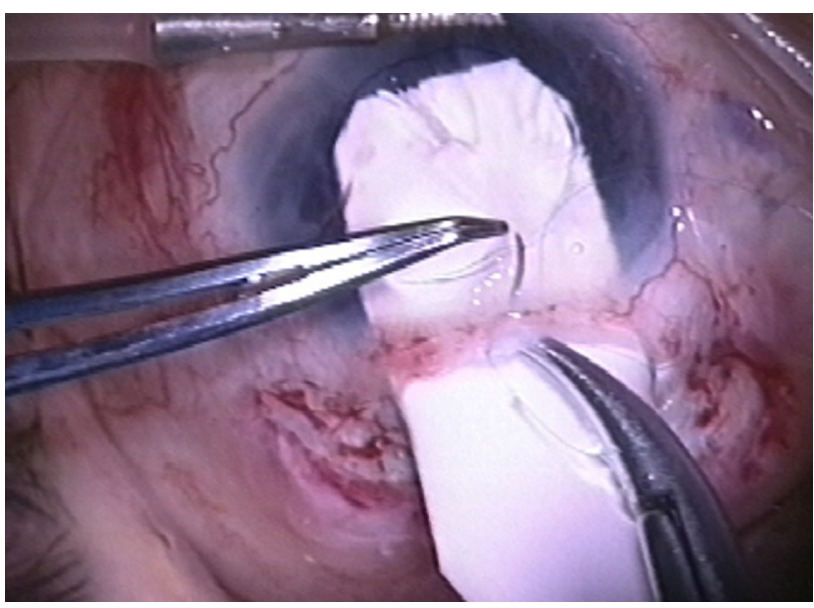

Figure 4 The curved needle is also entering the endothelial side of the recipient cornea and exiting the epithelial side at the point marked by the $7.0-\mathrm{mm}$ diameter trephine and 1.0-mm distance from which the straight needle passed through.

micro capsulorhexis forceps; Eye Technology, Essex, UK) to hold the edge of the stromal side of the lenticule.

Immediately after withdrawal of the anterior capsule forceps, the superior scleral tunnel was closed with 10-0 nylon. Both arms of the prolene suture were pulled until the lenticule attached to the recipient stroma, and air was supplied through the anterior chamber maintainer at $25 \mathrm{mmHg}$. The lenticule was positioned at the center of the cornea using a Sinskey hook, and the prolene sutures were tied onto the epithelium. The knot was not rotated into the recipient cornea. A removal of the anterior chamber maintainer was followed by infusion of perfluoropropane $\left(\mathrm{C}_{3} \mathrm{~F}_{8}\right)$ gas at concentrations of $15 \%-20 \%$ by superior paracentesis. While the patient rested for 15 minutes lying face-up before recovering from anesthesia, the recipient cornea was dressed several times to help drain residual fluid from the stromal interface. We prescribe lying in a face-up position whenever possible on the day of the surgery. The 10-0 prolene suture that was tied onto the epithelium was removed 2 weeks after the surgery.

\section{Case report}

This suture technique was applied in two cases with aniridia and aphakic bullous keratopathy without capsule support after vitrectomy for traumatic vitreoretinal disease.

Case 1 was a 39-year-old male who had a bilateral penetrating ocular globe injury that caused traumatic cataract, traumatic retinal detachment, traumatic aniridia, and vitreous bleeding bilaterally. After seven vitrectomies, his right vision was lost because of proliferative vitreoretinopathy. In his left eye, bullous keratopathy occurred, even though the retina was attached. His iris was widely dissected and peripheral anterior synechia occurred at 270 degrees. DSAEK was 
performed with the suture technique described. On the first postoperative day, the endothelial lenticule was not attached completely, although the $10-0$ prolene suture prevented the lenticule from falling out of the recipient cornea. Lying rigid face-up for 24 hours facilitated complete attachment. The endothelial lenticule attached in a good position and the best-corrected visual acuity (BCVA) was 20/50 at 2 years postoperatively.

Case 2 was a 76-year-old male, who had traumatic lens dislocation, traumatic aniridia, vitreous bleeding, and retinal detachment in his left eye. Bullous keratopathy occurred 1 year after vitrectomy. Although he underwent penetrating keratoplasty uneventfully, the corneal graft failed 2 years after the surgery because of secondary glaucoma due to peripheral anterior synechia at $330^{\circ}$. The described suture technique was applied to the bullous keratoplasty after the previous penetrating keratoplasty. The endothelial lenticule was not attached completely during the first week postoperatively, and $\mathrm{C}_{3} \mathrm{~F}_{8}$ gas infusion at concentrations of $20 \%-100 \%$ was repeated through paracentesis. Ten days postoperatively, the lenticule was attached without any additional procedures that stressed the lenticule mechanically. At 10 months after the surgery, the BCVA remained 20/320 because of an optic nerve disorder and a thick epiretinal membrane.

\section{Discussion}

In DSAEK for aniridic aphakic cases after vitrectomy with total lens removal, the endothelial lenticule may fall into the vitreous cavity. However, using this suture technique, the $10-0$ prolene suture tied on the epithelium successfully prevented the endothelial lenticule from being detached from the recipient cornea. Indeed, during surgery in both described cases, the endothelial lenticule was not detached, even at the moment that removal of the anterior chamber maintainer was followed by $\mathrm{C}_{3} \mathrm{~F}_{8}$ gas injection. Similarly, on the first postoperative day, the 10-0 prolene suture effectively attached the endothelial lenticule to the recipient corneal stroma at the suture sites in both cases, even after partial detachment of the endothelial lenticule from the recipient corneal stroma. Thus, the lenticule in both cases could have fallen into the vitreous cavity in the absence of the 10-0 prolene suture on the first postoperative day, even though the lenticule had been attached to the recipient cornea and had not moved at the end of the surgery. Although Sarnicola and Toro ${ }^{4}$ and Vajpayee et $\mathrm{al}^{5}$ used a 10-0 prolene suture in a similar manner, they cut and removed the suture during the surgery once the endothelial lenticule was centered and adherent to the recipient cornea. We have demonstrated that the $10-0$ prolene suture tied onto the epithelium works like a dress-pin during the surgery and it plays a crucial role in adhesion of the lenticule to the recipient stroma after the surgery. In addition, we marked the insertion sites of the double-armed needle with a 10-0 prolene suture on both the recipient epithelium and donor stroma with crystal violet, which may allow the lenticule to be centered well.

Patel et $\mathrm{al}^{8}$ have already reported similar suture techniques in DSAEK for 13 cases with minimal or absent iris-lens diaphragm. They also used a double-armed 10-0 prolene suture that was originally designed for intraocular lens ciliary sulcus fixation. In their procedure, however, both arms of a 10-0 prolene suture were passed through the lenticule completely before lenticule insertion, which may lead to tangling of the suture and the endothelial damage. They performed this suture technique in DSAEK in 13 cases. However, only one eye had both total iris defect and aphakia, and others had pseudophakia or partial iris defect. Price et $\mathrm{al}^{6}$ also reported suture technique in DSAEK for three cases with aniridia and aphakia. They applied trypan blue to the stromal surface of the folded donor tissue to aid in visualizing it after implantation in the anterior chamber. The staining donor tissue was initially inserted only $80 \%$ to $90 \%$ of the way into the eye leading to one end being held in the incision, while a temporary anchoring suture was placed in the peripheral edge of the anterior portion of the donor tissue to secure it to the overlying recipient cornea. The fixation suture used to anchor the donor tissue temporarily was then removed in two cases and left in one. Using their techniques, corneal decompensation was successfully treated in three consecutive cases with no iris and lens. Cagini et $\mathrm{al}^{10}$ reported three cases of simultaneous DSAEK and aphakic iris-fixated intraocular lens implantation for aphakia and bullous keratopathy. However, their cases had normal iris. Jastaneiah ${ }^{11}$ reported other procedure of DSAEK for traumatic aniridia and aphakia. The author planned surgery in two stages. The first stage was implantation of aniridia intraocular lens, and a few months later, DSAEK procedure was performed. However, vitreous was present in this case.

Disadvantages of applying this suture technique to DSAEK may involve two issues: (1) the difficulty of handling the prolene sutures, and (2) the risk of epithelial ingrowth or downgrowth. A 10-0 prolene suture may be difficult to handle, because they are less rigid than nylon sutures. Having to handle the tangled suture during lenticule manipulation may be a risk for mechanical damage to the endothelium. Macsai and Kara-Jose ${ }^{3}$ described passing one side of a double-armed needle through the edge of the donor lenticule, entering 
the endothelial surface, and exiting the stromal side. They indicated that passing the needle through the endothelial lenticule is a risk for focal endothelial damage and Descemet detachment. In our technique, the curved needle with the double-armed prolene suture is not passed through, but is placed in the stroma of the lenticule, so that only one side of the double-armed suture has to be handled. Consequently, both direct damage to the endothelium and risk for Descemet detachment may be avoided.

With regard to epithelial ingrowth or downgrowth after DSAEK, these adverse effects have been recently reported as rare postoperative complications. ${ }^{12-15}$ Some authors suggest that the invading epithelium originates from donor cornea, ${ }^{12,13}$ whereas others suggest that it originates from recipient tissues, including the conjunctiva. ${ }^{14,15}$ In theory, a wide sclerocornea wound due to trauma and paracentesis may be a risk factor for epithelial invasion into the anterior chamber from recipient tissues. ${ }^{14,16-18}$ In the technique described in this report, the $10-0$ prolene suture tied onto the recipient corneal epithelium, which penetrates through the recipient stroma into the endothelial lenticule, may be a risk factor for epithelial ingrowth. In our cases, wide sclerocornea wounds associated with open globe injury and wounds related to repeated three-port pars plana vitrectomy were evident prior to DSAEK. Such wounds may be risk factors for epithelial ingrowth or downgrowth. Gas tamponade may also be a risk factor for epithelial ingrowth or downgrowth. Indeed, in Case 1, whitish opacity suggestive of epithelial ingrowth occurred 6 months postoperatively, which had increased gradually between the host-graft interface, and the BCVA had reached a plateau of 20/50 at 2 years after DSAEK.

The difficulty of effective intraocular pressure control should be taken into account after DSAEK in aniridic aphakic cases after vitrectomy. In aphakic cases after vitrectomy with total lens removal, gas-mediated pupillary block and iridocorneal apposition can cause a secondary glaucoma. ${ }^{19,20}$ Although the former complication is unlikely to occur in aniridic cases, distensible gas in the vitreous cavity may possibly close the residual opened angle. In Case 2 , intraocular pressure became difficult to control and multiple eye drops for glaucoma were needed shortly after DSAEK.

Various findings indicate that cases with traumatic aniridia and aphakic bullous keratopathy after vitrectomy with total lens removal may not be good candidates for DSAEK. The surgical indication may vary with the type of injury. However, it is controversial whether such cases should be excluded from an indication for DSAEK or not.
One of the causes of this exclusion is probably the risk of endothelial lenticule dropping into the vitreous cavity. In this report, we prove that our suture technique using 10-0 prolene was a feasible approach for DSAEK in two cases of aniridic aphakic bullous keratopathy after vitrectomy with total lens removal. Such cases can be candidates for DSAEK, although further study is needed to determine whether penetrating keratoplasty should be chosen at first.

\section{Disclosure}

The authors have not received grant support or research funding and do not have any proprietary interests in materials described in the article.

\section{References}

1. Price MO, Price FW. Descemet's stripping automated endothelial keratoplasty. Curr Opin Ophthalmol. 2007;18(4):290-294.

2. Gorovoy MS. Descemet-stripping automated endothelial keratoplasty. Cornea. 2006;25(8):886-889.

3. Macsai MS, Kara-Jose AC. Suture technique for Descemet stripping and endothelial keratoplasty. Cornea. 2007;26(9):1123-1126.

4. Sarnicola V, Toro P. Descemet-stripping automated endothelial keratoplasty by using suture for donor insertion. Cornea. 2008;27(7): $825-829$.

5. Vajpayee RB, Agarwal T, Jhanji V, Sharma N. Modification in Descemet-stripping automated endothelial keratoplasty "Hitch suture" technique. Cornea. 2006;25(9):1060-1062.

6. Price MO, Price FW Jr, Trespalacios R. Endothelial keratoplasty technique for aniridic aphakic eyes. J Cataract Refract Surg. 2007; 33(3):376-379.

7. Eguchi H, Matsushita S, Inoue M, Oogi Y, Katome T, Shiota H. Three cases of DSEK using a ciliary sulcus fixation suture for endothelial lenticule insertion. Jpn J Ophthalmic Surg. 2008;22(1): 89-92.

8. Patel AK, Luccarelli S, Ponzin D, Busin M. Transcorneal suture fixation of posterior lamellar grafts in eyes with minimal or absent iris-lens diaphragm. Am J Ophthalmol. 2011;151(3):460-464.

9. Meisler DM, Dupps WJ Jr, Covert DJ, Koenig SB. Use of an air-fluid exchange system to promote graft adhesion during Descemet's stripping automated endothelial keratoplasty. J Cataract Refract Surg. 2007; 33(5):770-772.

10. Cagini C, Fiore T, Leontiadis A, et al. Simultaneous Descemet stripping automated endothelial keratoplasty and aphakic iris-fixated intraocular lens implantation: a case series. Cornea. 2011;30(10): $1167-1169$

11. Jastaneiah SS. Descemet's stripping-automated endothelial keratoplasty for traumatic aniridia and aphakia. Case Rep Ophthalmol Med. 2012; 2012:982657.

12. Koenig SB, Covert DJ. Epithelial ingrowth after Descemetstripping automated endothelial keratoplasty. Cornea. 2008;27(6): 727-729.

13. Shulman J, Kropinak M, Ritterbrand DC, et al. Failed Descemet-stripping automated endothelial keratoplasty grafts: A clinicopathological analysis. Am J Ophthalmol. 2009;148(5):752-759.

14. Bansal R, Ramasubramanian A, Das P, Sukhija J, Jain AK. Intracornal epithelial ingrowth after descemet stripping keratoplasty and stromal puncture. Cornea. 2009;28(3):334-337.

15. Phillips PM, Terry MA, Kaufman SC, Chen ES. Epithelial downgrowth after Descemet-stripping automated endothelial keratoplasty. J Cataract Refract Surg. 2009;35(1):193-196. 
16. Nagra PK, Raber IM. Epithelial ingrowth in a phakic corneal transplant patient after traumatic wound dehiscence. Cornea. 2003;22(2): 184-186.

17. Theobald GD, Haas JS. Epithelial invasion of the anterior chamber following cataract extraction. Ophthalmology. 1948;52:470-482.

18. Feder RS, Krachmer JH. The diagnosis of epithelial downgrowth after keratoplasty. Am J Ophthalmol. 1985;99(6):697-703.
19. AL-Shahwan S, Ghadhfan F, Kalantan H, Al-Torbak AA. Pupillary block glaucoma in phakic perfluoropropane gas filled eye. Br J Ophthalmol. 2006;90(6):797-798.

20. Gedde SJ. Management of glaucoma after retinal detachment surgery. Curr Opin Ophthalmol. 2002;13(2):103-109.
Clinical Ophthalmology

\section{Publish your work in this journal}

Clinical Ophthalmology is an international, peer-reviewed journal covering all subspecialties within ophthalmology. Key topics include: Optometry; Visual science; Pharmacology and drug therapy in eye diseases; Basic Sciences; Primary and Secondary eye care; Patient Safety and Quality of Care Improvements. This journal is indexed on
Dovepress

PubMed Central and CAS, and is the official journal of The Society of Clinical Ophthalmology (SCO). The manuscript management system is completely online and includes a very quick and fair peer-review system, which is all easy to use. Visit http://www.dovepress.com/ testimonials.php to read real quotes from published authors. 